\title{
SARS-CoV-2 Viral RNA Is Detected in the Bone Marrow in Post-Mortem Samples Using RT-LAMP
}

\author{
Tomasz Jurek ${ }^{1} \oplus$, Marta Rorat $^{1}$, Łukasz Szleszkowski $^{1}$, Miron Tokarski ${ }^{2} \oplus$, Izabela Pielka ${ }^{2}$ and \\ Małgorzata Małodobra-Mazur 1,2,3,*(D) \\ 1 Department of Forensic Medicine, Wroclaw Medical University, 50-345 Wrocław, Poland; \\ tomasz.jurek@umw.edu.pl (T.J.); marta.rorat@umw.edu.pl (M.R.); lukasz.szleszkowski@umw.edu.pl (Ł.S.) \\ 2 Genomtec Inc., Bierutowska Street 57-59, 51-317 Wroclaw, Poland; m.tokarski@genomtec.com (M.T.); \\ i.pielka@genomtec.com (I.P.) \\ 3 Department of Molecular Techniques, Wroclaw Medical University, 50-367 Wrocław, Poland \\ * Correspondence: malgorzata.malodobra-mazur@umw.edu.pl; Tel.: +48-71-7841587
}

Citation: Jurek, T.; Rorat, M.; Szleszkowski, Ł.; Tokarski, M.; Pielka I.; Małodobra-Mazur, M. SARS-CoV-2 Viral RNA Is Detected in the Bone Marrow in Post-Mortem Samples Using RT-LAMP. Diagnostics 2022, 12, 515. https://doi.org/10.3390/ diagnostics12020515

Academic Editor: Anna Baraniak

Received: 27 January 2022

Accepted: 15 February 2022

Published: 17 February 2022

Publisher's Note: MDPI stays neutral with regard to jurisdictional claims in published maps and institutional affiliations.

Copyright: (C) 2022 by the authors. Licensee MDPI, Basel, Switzerland. This article is an open access article distributed under the terms and conditions of the Creative Commons Attribution (CC BY) license (https:// creativecommons.org/licenses/by/ $4.0 /)$.

\begin{abstract}
Since the emergence of severe acute respiratory syndrome coronavirus 2 (SARS-CoV-2) in late 2019, viral RNA has been detected in several different human tissues and organs. This study reports the detection of SARS-CoV-2 RNA in the bone marrow. Post-mortem samples were taken in a sterile manner during two forensic autopsies from the nasopharyngeal region, vitreous humor, cerebrospinal fluid, and bone marrow. SARS-CoV-2 was subsequently diagnosed via Genomtec ${ }^{\circledR}$ SARS-CoV-2 EvaGreen ${ }^{\circledR}$ RT-LAMP CE-IVD Duo Kit. In both postmortem patients, SARS-CoV-2 RNA was detected in bone marrow samples. However, both the vitreous humor and cerebrospinal fluid from the same patients gave negative results using the same test system. The evidence of viral RNA in the bone marrow, along with other reports supports the thesis that SARS-CoV-2 infections are systemic in nature, the consequences of which would profoundly influence both the testing and survival of patients.
\end{abstract}

Keywords: SARS-CoV-2; bone marrow; RT-LAMP; detection; postmortem samples

\section{Introduction}

COVID-19 disease, caused by SARS-CoV-2 is a highly contagious infectious disease with a relatively high rate of death [1]. It is considered not only as a respiratory tract disease that affects the lungs but as a systemic disease affecting multiple organs such as the heart, brain, nervous system, liver, kidney, digestion truck, and others [2]. Since the emergence of severe acute respiratory syndrome coronavirus 2 (SARS-CoV-2) in late 2019, viral RNA has been detected in several different human tissues and organs. Except for lungs, RNA of SARS-CoV-2 was detected in the liver, heart, kidney, spleen, pancreas, gallbladder, small and large intestine, common carotid artery, and others [2]. For some specific tissue locations, it is hard to obtain biological samples from living subjects, that is why numerous reports describe SARS-CoV-2 detection postmortem, which allows determining almost all possible organs in terms of the presents of SARS-CoV-2 and possible consequences of COVID-19 [2].

The nucleic acid amplification tests (NAAT) utilizing nasopharyngeal swabs are the most common and sensitive methods for confirming the SARS-CoV-2 infection [3], with the most widely used technique for SARS-CoV-2 diagnosis being Real-Time PCR. However, other amplification techniques have recently been introduced, characterized by higher specificity and sensitivity, with a shorter time to results. These methods include loopmediated isothermal amplification (LAMP) [4].

Viral RNA detection can provide vital information on modes of transmission and more importantly highlight previously hidden pools of infection within the human body, thus improving the prognosis and survival rate of COVID-19 patients. In our study we search the SARS-CoV-2 presents in not typical organs that little has been done so far, that is 
vitreous humor, cerebrospinal fluid, and bone marrow. We used postmortem samples for our study.

\section{Materials and Methods}

The protocol of this study was approved by the Bioethical Committee Board of Wroclaw Medical University (No. KB826/2020).

\subsection{Sample Characterization}

Post-mortem samples were taken in a sterile manner during two forensic autopsies. Nasopharyngeal swabs (N), vitreous humor (V), cerebrospinal fluid (C) by sub-occipital puncture, and bone marrow (B) by aspiration from the posterior superior iliac crest were collected. Samples were taken 12 days after death and immediately placed in transport media (UTM, Biocomma), then transferred to the laboratory, maintaining a chilled environment throughout. The medical records have also been analyzed.

\subsection{RNA Extraction and Ampflication}

Viral RNA was extracted using QIAamp ${ }^{\circledR}$ DSP Virus Spin Kit (Qiagen, Hilden, Germany) according to the manufacturer's protocol. Eluted RNA was subjected to nucleic acid amplification using Genomtec ${ }^{\circledR}$ SARS-CoV-2 EvaGreen ${ }^{\circledR}$ RT-LAMP CE-IVD Duo Kit (Genomtec, Wroclaw, Poland) according to manufacturer's instruction. Two SARS-CoV2-specific gene fragments ( $N$ gene and $S$ gene) and one human RPP30 gene (inhibition control) were amplified using RT-LAMP. The diagnostic process was performed using the CFX96 Dx in vitro diagnostic system (BioRad, Hercules, CA, USA). Dedicated software was used for results visualization and interpretation. Amplification results were confirmed by $2 \%$ agarose gel electrophoresis.

\section{Results}

Case 1. An 89-year-old man with hypertension, senile dementia and gout died within 19 days of COVID-19 diagnosis (confirmed by RT-PCR). Laboratory diagnostics performed during hospitalization did not reveal significant abnormalities except a moderate increase in inflammatory markers and lymphopenia. The main post-mortem pathologic findings were: severe, dense, consolidating infiltrates in both lungs; diffused alveolar damages in each lobe and edema in the bronchial mucosa; cardiomegaly; splenomegaly; and liver steatosis. The cause of death was acute respiratory distress syndrome. When analyzed via LAMP amplification, SARS-CoV-2 RNA was detected in bone marrow (B), but not in the vitreous humor (V) or cerebrospinal fluid (C) (Figure 1A,C, Table 1).

Case 2. A 91-year-old woman with chronic circulatory failure, ischemic heart disease, chronic kidney disease, type 2 diabetes with asymptomatic SARS-CoV-2 infection, died 9 days after a positive RT-PCR nasopharyngeal test. There were no post-mortem findings indicative of COVID-19, although advanced atherosclerosis, chronic pulmonary emphysema, multinodular goiter, liver steatosis, and pancreatic fibrosis were diagnosed. The cause of death was diabetic ketoacidosis. When analyzed SARS-CoV-2 RNA was detected in bone marrow (B) and nasopharyngeal swab (N), but not in the vitreous humor $(\mathrm{V})$ or cerebrospinal fluid (C) (Figure 1B,C, Table 1).

Summarizing, in both patients SARS-CoV-2 RNA was detected postmortem in the bone marrow and for patient 2 the virus was also found in the nasopharyngeal swab. However, in neither case was viral RNA detected in either vitreous humor or cerebrospinal fluid. The positive control of SARS-CoV-2 RNA (Quantitative PCR (qPCR) Control RNA from Heat-Inactivated SARS-Related Coronavirus 2, Isolate USA-WA1/2020) gave a positive signal, and the no-template controls (NTC) were negative for both tests. 

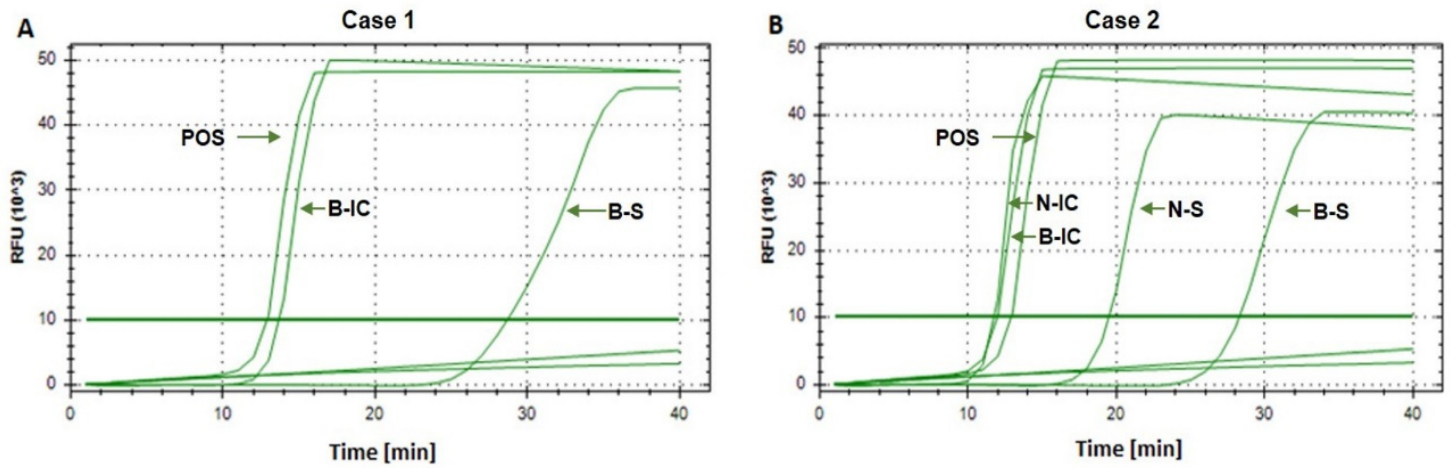

C

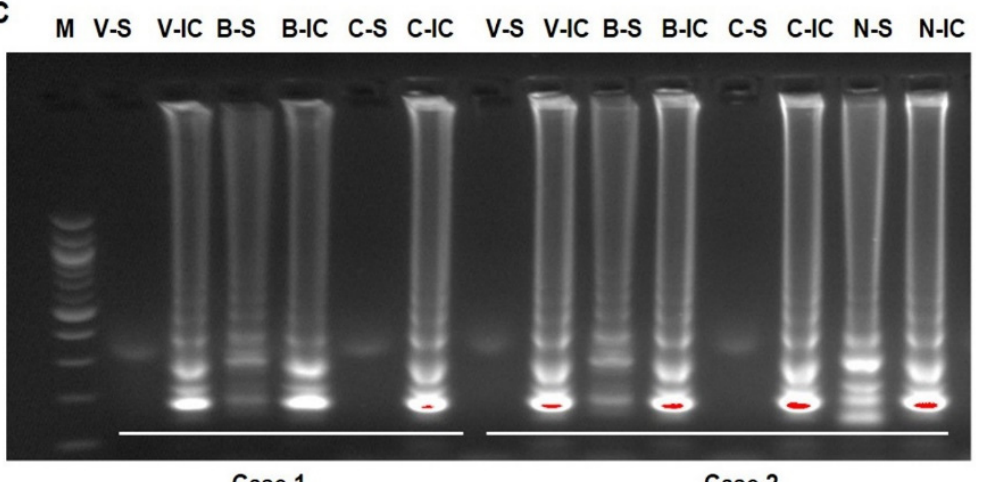

Case 1

Case 2

Figure 1. SARS-CoV-2 detection in postmortem collected samples. The real-time SARS-CoV-2 detection using Genomtec ${ }^{\circledR}$ SARS-CoV-2 EvaGreen ${ }^{\circledR}$ RT-LAMP CE-IVD Duo Kit from two clinical cases ((A) — case 1, (B) — case 2). The confirmation of obtained results by agarose gel electrophoresis (C). POS-positive sample with the standard genetic material of SARS-CoV-2; B-IC-bone marrowinhibition control; B-S-bone marrow-SARS-CoV-2; N-IC-nasopharyngeal swab-inhibition control; N-S-nasopharyngeal swab-SARS-CoV-2; V-IC—vitreous humor-inhibition control; V-S-vitreous humor-SARS-CoV-2; C-IC-Cerebrospinal fluid-inhibition control; C-S-Cerebrospinal fluidSARS-CoV-2.

Table 1. The Real-Time LAMP results of analyzed clinical cases. The table represents the time to detection of a particular sample using Genomtec ${ }^{\circledR}$ SARS-CoV-2 EvaGreen ${ }^{\circledR}$ RT-LAMP CE-IVD Duo Kit (N/A-not detected).

\begin{tabular}{ccccc}
\hline \multirow{2}{*}{ Sample } & \multicolumn{2}{c}{$\begin{array}{c}\text { Case 1 } \\
\text { Time to Results [min] }\end{array}$} & \multicolumn{2}{c}{ Case 2 } \\
& Time to Results [min] \\
\cline { 2 - 5 } & SARS-CoV-2 & IC & SARS-CoV-2 & IC \\
\hline $\begin{array}{c}\text { Nasopharyngeal swab } \\
\text { (N) }\end{array}$ & Not tested & Not tested & 19.48 & 11.91 \\
\hline Vitreous humor (V) & N/A & 22.02 & N/A & 17.21 \\
\hline Cerebrospinal fluid (C) & N/A & 17.18 & N/A & 14.33 \\
\hline Bone marrow (B) & 28.70 & 13.67 & 28.28 & 11.73 \\
\hline Positive Control * & & \multicolumn{3}{c}{12.45} \\
\hline NTC & & N/A
\end{tabular}

*(Quantitative PCR (qPCR) Control RNA from Heat-Inactivated SARS-Related Coronavirus 2, Isolate USAWA1/2020, BEI Resources); NTC—No-template Control; IC—internal control; N/A—Not detected.

\section{Discussion}

Despite both SARS-CoV-2 patients being diagnosed over one week before death and the samples being taken 12 days after death, SARS-CoV-2 RNA remained detectable 
in the bone marrow of both examined patients. Significant disparities in the clinical course did not affect the detection of the RNA. The presence of viral RNA in the bone marrow and nasopharyngeal swab (case 2 only) indicates that both might represent equally advantageous environments for the virus to survive and replicate. In other published data, the presence of viral RNA has been detected in a variety of clinical samples including the lungs, bronchi, lymph nodes, spleen, heart, liver, kidney, brain, feces, blood, urine, and semen [5-9]. All the current research indicates that SARS-CoV-2 may spread via the bloodstream throughout the organism. This systemic spread would allow for the infection of the bone marrow, which due to its immune-related functions, would likely have a significant impact on the type and intensity of inflammatory response, thus affecting the chances of survival.

Some reports indicated previously that SARS-CoV-2 might be detected in the bone marrow. Deinhardt-Emmer et al. [10] reported SARS-CoV-2 in bone marrow in three out of eleven investigated samples collected postmortem. On the other hand, Massoth et al. [11] did not confirm the presence of SARS-CoV-2 in bone marrow collected postmortem either using RNA In situ hybridization or immunohistochemistry techniques. However, the negative results might be also related to the low sensitivity used in the study methods, as in both techniques there is no amplification of viral RNA.

In this preliminary communication, we used the isothermal method that allowed for a semi-quantitative assessment of viral RNA, with the positive test obtained in both cases with a time to result of below 30 minutes from the start of the amplification process. Further conclusions will be possible after future in-depth research including the testing of a larger population of the infected patients, quantitative assessment of genetic material, viral culture, detecting virus components, assessment of infection and replication, and potentially the characterization of inflammatory changes in the bone marrow.

\section{Conclusions}

The evidence of viral RNA in the bone marrow found during this study confirms that SARS-CoV-2 infections may indeed be systemic in nature, and thus the detection of the virus in this location could have a significant influence on future strategies not only in viral biology research but also in therapeutic interventions.

Author Contributions: Conceptualization, T.J. and M.R.; methodology, M.M.-M., Ł.S., I.P.; formal analysis, M.R.; investigation, M.M.-M.; resources, M.T.; data curation, Ł.S.; writing-T.J. and M.M.-M.; writing-T.J., M.T.; funding acquisition, T.J., M.T. All authors have read and agreed to the published version of the manuscript.

Funding: This research was funded by project No. SUBZ.A120.22.077 (Wroclaw Medical University, Poland). This work was carried out according to the subject register in the Simple system of Wroclaw Medical University SUBZ. A120.22.077 and supported by a statutory subsidy granted by the Ministry of Science and Higher Education in Poland.

Institutional Review Board Statement: The study protocol was approved by the Bioethical Review Board of Wroclaw Medical University, no KB826/2020 (17 September 2020).

Informed Consent Statement: Not applicable.

Data Availability Statement: Data are available on request from the corresponding author.

Conflicts of Interest: The authors declare no conflict of interest.

\section{References}

1. Huang, C.; Wang, Y.; Li, X.; Ren, L.; Zhao, J.; Hu, Y.; Zhang, L.; Fan, G.; Xu, J.; Gu, X.; et al. Clinical features of patients infected with 2019 novel coronavirus in Wuhan, China. Lancet 2020, 395, 497-506. [CrossRef]

2. Menezes, R.G.; Rizwan, T.; Ali, S.S.; Hassan, W.; Khetpal, A.; Aqil, M.; Madadin, M.; Siddiqi, T.J.; Usman, M.S. Postmortem findings in COVID-19 fatalities: A systematic review of current evidence. Leg. Med. 2022, 54, 102001. [CrossRef] [PubMed] 
3. WHO Laboratory Testing for 2019 Novel Coronavirus (2019-nCoV) in Suspected Human Cases. Interim Guidance. Available online: https: / / www.who.int/publications-detail/laboratory-testing-for-2019-novel-coronavirus-in-suspected-human-cases20200117 (accessed on 17 January 2020).

4. Ganguli, A.; Mostafa, A.; Berger, J.; Aydin, M.Y.; Sun, F.; Ramirez, S.; Valera, E.; Cunningham, B.T.; King, W.P.; Bashir, R. Rapid isothermal amplification and portable detection system for SARS-CoV-2. Proc. Natl. Acad. Sci. USA 2020, 117, $22727-22735$. [CrossRef] [PubMed]

5. Perchetti, G.A.; Nalla, K.A.; Huang, M.L.; Zhu, H.; Wei, Y.; Stensland, L.; Loprieno, M.A.; Jerome, K.R.; Greninger, A.L. Validation of SARS-CoV-2 detection across multiple specimen types. J. Clin. Virol. 2020, 128, 104438. [CrossRef]

6. Sekulic, M.; Harper, H.; Nezami, B.G.; Shen, D.L.; Sekulic, S.P.; Koeth, A.T.; Harding, C.V.; Gilmore, H.; Sadri, N. Molecular Detection of SARS-CoV-2 Infection in FFPE Samples and Histopathologic Findings in Fatal SARS-CoV-2 Cases. Am. J. Clin. Pathol. 2020, 154, 190-200. [CrossRef] [PubMed]

7. Wichmann, D.; Sperhake, J.P.; Lütgehetmann, M.; Steurer, S.; Edler, C.; Heinemann, A.; Heinrich, F.; Mushumba, H.; Kniep, I.; Schröder, A.S.; et al. Autopsy Findings and Venous Thromboembolism in Patients With COVID-19: A Prospective Cohort Study. Ann. Intern. Med. 2020, 173, 268-277. [CrossRef]

8. Wang, W.; Xu, Y.; Gao, R.; Lu, R.; Han, K.; Wu, G.; Tan, W. Detection of SARS-CoV-2 in Different Types of Clinical Specimens. JAMA 2020, 323, 1843-1844. [CrossRef] [PubMed]

9. Massarotti, C.; Garolla, A.; Maccarini, E.; Scaruffi, P.; Stigliani, S.; Anserini, P.; Foresta, C. SARS-CoV-2 in the semen: Where does it come from? Andrology 2020, 9, 39-41. [CrossRef] [PubMed]

10. Deinhardt-Emmer, S.; Wittschieber, D.; Sanft, J.; Kleemann, S.; Elschner, S.; Haupt, K.S.; Vau, V. Early postmortem mapping of SARS-CoV-2 RNA in patients with COVID-19 and the correlation with tissue damage. Elife 2021, 30, e60361. [CrossRef] [PubMed]

11. Massoth, L.R.; Desai, N.; Szabolcs, A.; Harris, C.K.; Neyaz, A.; Crotty, R.; Chebib, I.; Rivera, M.N.; Sholl, M.N.; Stone, J.R.; et al. Comparison of RNA In Situ Hybridization and Immunohistochemistry Techniques for the Detection and Localization of SARSCoV-2 in Human Tissues. Am. J. Surg. Pathol. 2021, 45, 14-24. [CrossRef] [PubMed] 